\title{
A multivocalidade da cura na saúde mental: uma análise do discurso psiquiátrico
}

\author{
M ultiple voices of healing in mental health: \\ an analysis of psychiatric discourse
}

Vládia Jamile dos Santos Jucá 1

\footnotetext{
1 Departamento de Ciências Humanas, Universidade de Salvador, Campus I guatemi. Alameda das Espasmódias 915, Caminho das Árvores 41820-460, Salvador BA. vladiajamile@terra.com.br
}

Abstract This paper presents some of the results of the thesis The meanings of healing in mental health, that had as one of its core objectives the investigation of healing's meaning to outpatients, families and psychiatrists of a mental health hospital. The methodological frame of the research was the Signs, M eanings and Practices Theory, through which we look for to observe how the subjects have built conceptions and expectations based on their experiences with the mental suffering. In this paper we discuss the results from the analysis of psychiatrists' speeches, where it is possible to notice that the healing conceptions are closely related to the following elements: (a) the pathology; (b) the etiological conceptions of the subject and (c) the expectations on the future of psychiatry.

Key words Healing, Psychiatric, Outpatient service
Resumo 0 presente artigo apresenta alguns dos resultados da tese de doutorado intitulada Os sentidos da cura em saúde mental, que tinha como um de seus objetivos centrais a investigação dos significados da cura para psiquiatras, familiares e usuários de um ambulatório de saúde mental. $\mathrm{N}$ a realização da pesquisa, foi utilizada a metodologia denominada Signos, Significados e Práticas, através da qual procuramos observar como os sujeitos construíam concepções e expectativas acerca da cura a partir de suas experiências com o sofrimento mental. Discutiremos a seguir os resultados construídos a partir da análise do discurso dos psiquiatras, em que é possí vel perceber que a noção de cura está intimamente relacionada aos seguintes elementos: (a) a patologia da qual se fala; (b) as concepções etiológicas dos entrevistados; e (c) as expectativas sobre o futuro da psiquiatria.

Palavras-chave Cura, Psiquiatria, Ambulatório 


\section{A cura como um tabu}

Para falar sobre cura em psiquiatria, é preciso ter cautela. "Pisar com os pés descalços, sem pele", como diz uma canção popular. Se curar já foi al vo da intervenção psiquiátrica, hoje, o termo parece ter adquirido o caráter de um tabu na ordem da linguagem. U ma de nossas entrevistadas, a enfermeira identificada como E1, por exemplo, afirmou: "Cura... é uma coisa arriscada você falar em cura". 0 interdito que circunda a cura, no campo psiquiátrico, possui suas razões de existir, que dizem respeito, por um lado, ao passado da psiquiatria e, por outro, à impossibilidade de circunscrever a discussão sobre a cura a uma questão técnica: $\mathrm{Pa}$ ra os pesquisadores da medicina clínica, cura é uma palavra embaraçante. Ela expõe as raízes arcaicas da medicina e da psiquiatria; raízes que são comumente escondidas sob a face da ciência biomédica de assistência à saúde atual. I sto suge re o quão pouco realmente sabemos acerca da função mais central do cuidado clínico. Isto condiz muito bem com as críticas levantadas pelos pacientes e consumidores em geral do sistema de saúde. I sto levanta indagações que mexem com os significados e valores atribuídos pelo homem que não são facilmente reduzíveis a questões que podem ser respondidas com simples explicações biológicas (Kleinman \& Sung, 1979).

O silêncio sobre a cura no campo psiquiátrico se torna mais visível quando tentamos compilar material bibliográfico acerca do tema. Recentemente, encontramos alguns autores que defendem a necessidade de retomarmos a discussão sobre o tema, mesmo que seja para redefinir o conceito de cura no campo psiquiátrico (Teixeira, 1999; Bezerra J r., 1992; Goldberg, 2001). $\mathrm{Na}$ antropologia, encontramos, com certa facilidade, referências sobre a cura em relação a um outro sistema de cuidados: a religião. Desde o clássico A eficácia simbólica de Lévi-Strauss (1975), até pesquisas real izadas na atualidade e em solo brasileiro, temos uma rica discussão acerca do assunto.

Por outro lado, encontramos al gumas preciosas reflexões sobre os elementos definidores de um tratamento bem-sucedido, no campo da saúde mental. Tais estudos nos ajudarão a levantar algumas questões preliminares acerca do que poderia ser interpretado como uma intervenção psiquiátrica bem-sucedida. Kleinman (1978), por exemplo, afirma que o tratamento de uma doença é avaliado como bemsucedido quando o sofrimento recebia uma ex- plicação significativa para o sujeito e quando ele conseguia lidar com as questões socioculturais presentes em seu sofrimento. Assim sendo, não é tão surpreendente o resultado da pesquisa de Kleinman \& Sung (1979), na qual se observou que uma parte significativa de pacientes (10 de 12 casos), tratados por curandeiros chineses (tâng-kis), consideravam-se, pelo menos, parcialmente curados, apesar de nem sempre os sintomas psicológicos terem desaparecido por completo. Esta avaliação positiva da intervenção dos tâng-kis, por parte de seus pacientes, era devida, segundo os autores, a mudanças operadas em suas redes relacionais, nas quais os sujeitos assumiam novas posições. Ou seja, a ausência de sintomas não era o critério mais importante para uma avaliação positiva do tratamento.

Hydén (1995) também se preocupa em refletir sobre o que se poderia definir como um tratamento bem-sucedido na área da saúde mental. Como ponto de partida, ele analisa as narrativas de pessoas que, após uma psicoterapia, consideram-se curadas de uma situação de vida problemática. É importante acentuar que o estudo de Hydén teve como pano de fundo o tratamento psicoterápico, e não o psiquiátrico, dois campos extremamente diferenciados, apesar de suas similaridades: o compartilhamento do mesmo objeto de intervenção - o psiquismo humano - e, uma mesma marca histórica na sua construção, a problematização da fronteira entre o normal e o patológico.

M esmo ciente das diferenças significativas entre os dois tipos de abordagem do sofrimento psíquico, o texto de Hydén traz observações preciosas para nossa discussão, das quais destacaremos as seguintes:

A recuperação de uma enfermidade ou da condição de doente mental deve ser compreendida como uma reorganização de elementos culturais, sociais e psicológicos que, conjuntamente, podem determinar se um tratamento foi bem-sucedido.

A recuperação adquire sentido no contexto das aspirações e da auto-imagem de cada sujeito, tornando-se parte do modo pelo qual ele avalia sua vida.

Nos relatos dos "recuperados", a narrativa é construída como um enredo dramático: uma vida cheia de tormentos antes do tratamento é seguida pelo adoecimento (the breakdown) que, por sua vez, determina o ingresso no processo terapêutico e, por fim, a aquisição de uma nova vida. Hydén retoma, sobre este as- 
pecto, M ishler e Good, para afirmar que é possível destacar, de modo geral, nas narrativas de recuperação, três momentos: uma situação problemática surge, uma ação é adotada e o problema é resolvido.

N os casos que analisamos em nossa pesquisa, foi possível observar os dois primeiros pontos acima citados, sendo fundamental notar que "recuperação" não equivale à cura no campo psiquiátrico. Em psiquiatria, a recuperação designa, mais comumente, a saída de um estado de crise (ou da fase aguda). No entanto, a recuperação pode indicar ainda o processo através do qual pacientes, que romperam com um ciclo de crises e internações, tentam reconstruir suas vidas, interrompidas por um período de imersão no ambiente hospitalar. Estes pacientes são geralmente reconhecidos, pelos profissionais, como "estabilizados", "compensados" ou "em remissão".

0 processo de recuperação não se confunde, no entanto, com uma resolução absoluta, mas é sempre pensada como provisória. M ais do que isso, em alguns casos, por motivos diversos, predomina a expectativa da recaída. Nos casos de esquizofrenia, a expectativa de recaída é acentuada. Aliás, podemos afirmar que, dentre todas as patologias, esta se configura como a representante-mor da incurabilidade.

Conhecendo o prognóstico esperado para a esquizofrenia, ficamos curiosos acerca do que diria o Manual Diagnóstico e Estatístico de Transtornos M entais (DSM -IV) acerca dos possíveis cursos da doença. A cura, por exemplo, apareceria como uma possibilidade? Consultando o manual, encontramos uma classificação dos cursos da doença que se apresenta do seguinte modo:

- Episódico com sintomas residuais entre os epi sódios (acontecem várias crises, ao longo do tempo, permanecendo o paciente com alguns sintomas entre estes episódios);

- Episódico sem sintomas residuais entre os epi sódios (acontecem várias crises, ao longo do tempo, porém, entre um episódio e outro, 0 paciente não apresenta nenhum sintoma residual);

- Contínuo (os sintomas estão presentes 0 tempo todo);

- Episódio único com remissão parcial (uma crise apenas com a permanência de sintomas após a fase aguda);

- Episódio único com remissão completa (apenas uma crise sem permanência de sintomas após a fase aguda).

\section{Outro padrão ou padrão inespecificado}

O quinto caso, episódio único com remissão completa, seria o que mais próximo teríamos da cura, termo que não é utilizado, como pode ser visto. Assim, é difícil encontrar casos em que o problema seja considerado resolvido, de modo diferente das situações de psicoterapia consideradas por Hydén. No campo psiquiátrico, a resolução é sempre frágil. Especialmente para os pacientes psicóticos, com o histórico de várias internações. Para estes, o reaparecimento da doença permanece sempre no horizonte de suas vidas.

\section{Quando é possível falar em cura?}

No nosso trabalho de campo, o embaraço em abordar a cura se fez presente. Indagar sobre essa noção, principalmente quando a pergunta se dirigia aos profissionais do ambulatório, não era fácil. Sabíamos estar tratando de um tematabu, relegado ao esquecimento no campo psiquiátrico, o que não nos deixava em posição confortável. Em alguns momentos, havia a sensação de estar lançando de maneira forçada uma questão, posto que a cura não faz parte do horizonte da prática ambulatorial. 0 trabalho teve continuidade e, no entanto, por se considerar que o desaparecimento de uma concepção tão cara à identidade da medicina, no campo psiquiátrico, não poderia acontecer sem deixar rastros ou sem abrir outros horizontes.

De qual quer modo, entre resistências e embaraços, a pergunta era lançada. Para os psiquiatras, a "cura" era sempre compreendida como solução definitiva e a resposta sempre retornava de modo cauteloso. Por parte dos pacientes e familiares, mesmo quando havia alguma angústia presente, a resposta era apresentada com maior fluidez. U ma diferença fundamental éque, para os profissionais, a pergunta sempre se desdobrava entre as perspectivas de cura, no presente, eas que podem surgir com 0 suposto avanço da psiquiatria, enquanto para pacientes e familiares tratava-se sempre das expectativas acerca do que se pode obter a partir do tratamento em sua configuração atual.

Considerando a discussão acerca das concepções etiológicas e práticas terapêuticas levantada por Laplantine (1991), veremos que, no campo psiquiátrico, as relações se tornam particularmente complexas, por fatores que tentaremos evidenciar através das narrativas de nossos entrevistados. N este momento, é im- 
portante reforçar que a relação etiologia e terapêutica nos interessa, na medida em que o primeiro termo se refere ao nascimento do patológico, enquanto o segundo diz respeito à construção de um futuro para a doença que pode ser sua eliminação, seu controle ou sua cronificação.

Entre os profissionais, há um certo consenso acerca da etiologia das doenças mentais que acompanha os manuais de psiquiatria, no sentido da multifatorialidade ou multideterminação da doença. A repetição deste saber consagrado não significa que os vários determinantes adquirem o mesmo valor para todos os profissionais. Além do mais, a concepção multifatorial continua sendo compreendida como uma compilação de el ementos que podem causar ou agravar uma determinada patologia. Neste sentido, concordamos com Sinding (1995): As noções de etiologia multifatorial e de polimorfismo genético notadamente conduzem a uma apreensão plural, no entanto fragmentada, da saúde e da doença.

A idéia de multideterminação na saúde mental continua a ser considerada um somatório dos fatores sociais, orgânicos, culturais e "dinâmicos" (psicológicos), pouco se problematizando as inter-relações mais intrínsecas e constitucionais destes fatores, que aparecem como campos fechados, independentes, interagindo na construção da doença mental. U ma compreensão alternativa seria considerar que se trata de dimensões do humano que nascem integradamente, ligadas por um cordão umbilical que não se rompe. N ão obstante, através de um esforço analítico, tais dimensões podem ser percebidas como campos diferenciados.

Sentimos, nas entrevistas, que a primeira noção de multideterminação ganha - ou seja, trata-se de campos fechados que interagem - e, não apenas isso, acaba se estabel ecendo uma certa hierarquia entre os fatores. Eles não possuem o mesmo peso para todos. 0 "apego" a um dos determinantes é comum entre os profissionais, o que é compreensível a partir de suas trajetórias de vida pessoais e profissionais que fortalecem um modo de interpretar etiologicamente o sofrimento mental e determinam a escolha de uma ou mais terapêuticas.

$N$ a discussão etiológica, o DSM - IV é particularmente intrigante, quando tomamos o caso da esquizofrenia, por exemplo, por não trazer nenhuma seção dedicada especificamente à etiologia. A associação da doença com "anormalidades estruturais e funcionais", no entan- to, édiscutida com cuidado. 0 que revela a preferência por uma vertente organicista. 0 manual, em questão, observa que com relação às "anormalidades" existem controvérsias, mas, por outro lado, reforça a leitura da doença causada por malformações ou disfunções, quando afirma, por exemplo: Alguns déficits neuropsicológicos são consi derados reflexos de aspectos mais profundos da doença, etalvez revelem fatores de vulnerabilidade para a Esquizofrenia. Esses déficits são clinicamente significativos na medida em que estão ligados ao grau de dificuldade que alguns indivíduos têm com atividades da vida diária, bem como a capacidade de adquirir habilidades e reabilitação psicossocial.

A ausência de uma problematização maior dos fatores etiológicos no DSM -IV não surpreende, haja vista que sua nosologia é fundamentalmente descritiva. Os fenômenos, ou seja, as doenças, são organizados segundo a presença de um grupo de sintomas. Por isso, a reflexão sobre as causas é substituída pelas "características descritivas", pelos "transtornos mentais associados" ou pelos "achados laboratoriais associados". A psiquiatria, seguindo a referência do DSM -IV é paradoxal, pois, ao mesmo tempo em que penetra o corpo para explorar motivos anátomo-patológicos e razões funcionais associados à doença, permanece como um saber de superfície, centrando-se na descrição e catal ogação dos sintomas.

U ma outra referência importante para os psiquiatras que entrevistamos é o $M$ anual de Psiquiatria Clínica, escrito por Kaplan \& Sadock (1998). 0 manual em questão sistematiza os vários fatores que compõem a esquizofrenia, mas lembra logo de início: D evido à heterogeneidade das apresentações sintomáticas e prognósticas da esquizofrenia, nenhum fator etiológico isolado é considerado como causador. 0 modelo estresse-diátese é usado com maior freqüência, segundo o qual a pessoa que desenvolve esquizofrenia tem uma vulnerabilidade biológica específica, ou diátese, que, ativada pelo estresse, leva a sintomas esquizofrênicos. Os estresses podem ser genéticos, biológicos, psicossociais ou ambientais.

Esse parágrafo é uma excelente ilustração de que o discurso multifatorial existe, mas não mascara com eficiência as preferências, no caso, expressas pela "vulnerabilidade biológica". Outro ponto a ser destacado, no manual, éa divisão dos fatores etiológicos (classificados em genéticos, biológicos, psicossociais e ambientais), em que os fatores biológicos se subdivi- 
dem e são apresentados como hipóteses: (1) hipótese dopamínica; (2) hipótese da noradrenalina; (3) hipótese do ácido-aminobutírico; (4) hipótese da serotonina. Não deixa de ser intrigante que mesmo se tratando de "hipóteses", acerca das quais existem tantas controvérsias, não se abale a firme convicção de que, na raiz do sofrimento mental, reside uma susceptibilidade biológica.

Os paradoxos refletidos nos manuais encontram-se também nos psiquiatras entrevistados. Vamos inicialmente nos centrar na psiquiatra apresentada como PSQ 7. Ela nos lembra que a formação médica precisa ser abrangente pelas próprias características de seu objeto de intervenção, o homem em sua integralidade, no seu dizer "aquele ser biopsicossocial". Por outro lado, reconhece a dificuldade de manter uma conduta condizente com a compreensão holística, pois a própria construção da identidade profissional envolveria a realização de al gumas escolhas, por exemplo, a de ser adepto da psiquiatria biológica.

Entre a tentativa de compreender o "ser biopsi cossocial" e a adesão a uma vertente existe um processo interessante de descolamento entre o discurso que continua a ser multifatorial e a prática que valoriza uma compreensão etiológica. 0 caso da psiquiatra em questão é ilustrativo, posto que, ao mesmo tempo em que afirma a complexidade da doença mental, seus anos de prática fazem com que valorize significati vamente a compreen são orgânica: $\mathrm{Na}$ minha prática eu cheguei à conclusão, depois desses anos todos, que muitas das doenças que a gente tem realmente são orgânicas. Porque ficava me batendo ali, esquizofrenia, anos, quando você vai ver, o paciente tem anormalidade grave no eletro. Então, hoje em dia, eu já peço, para todos os pacientes, eu peço eletro.

A possível etiologia orgânica das doenças mentais se desdobra na narrativa da psiquiatra, cobrindo desde viroses, chás de uso popular, problemas gestacionais até condições insalubres de trabalho. A tendência a considerar que boa parte dos problemas mentais tem fundo orgânico leva à adoção da terapia medicamentosa, mesmo quando a patologia mostra-se nebulosa. Assim, para a psiquiatra em questão, a multideterminação da doença é substituída, no seu cotidiano, por uma adesão maior à etiologia orgânica e a intervenções terapêuticas consoantes com tal compreensão. E acerca da cura? 0 que pensaria nossa entrevistada? Em sua opinião, casos de cura são possíveis e ela nos fornece um exemplo: A gora mesmo, veio aqui meu eletricista pedir para fazer um atendimento do neto dele [...] Veio o menino, eu nem lembro direito o que era, eu só sei que eu fiz o primeiro atendimento, passei alguma medicaçãozinha bem discreta, bem leve, fiz as orientações e segundo 0 avô o menino está bom, nem trouxe mais de volta aqui, isso acontece muito. [...] Como é um garoto de 18 anos, você deixa correr mais solto, quanto menos medicar melhor, quanto menos entrar dentro do esquema de uma instituição melhor para não ficar instituído, cronificado. Têm umas situações que você trabalha muitos anos com o paciente, ele vai indo, vai meIhorando, vai melhorando, até... ou leva períodos que o paciente fica bom, sem sentir nada, vivendo bem, um ano, dois anos, aí chega uma hora acontece alguma coisa, algum estresse, morreu alguém da família, aí piora e ele volta.

A idéia de cura aqui condiz bem com o conceito psiquiátrico de "episódio único com remissão completa" que, como a própria entrevistada ressalta, não garante um futuro isento de novas crises. Aliás, ser ou não um episódio único é algo que só pode ser determinado a posteriori, considerando que o episódio foi único até aquele momento e, se assim permanecerá, só o futuro dirá. A psiquiatra nos fornece, assim, um possível sentido, ou talvez fosse meIhor pensar, um substituto para a cura no campo psiquiátrico: o episódio único com remissão completa, que não exime a possibilidade, conforme afirmamos, do surgimento de novos episódios no futuro. Uma cura, portanto, instável.

A possibilidade de falar em cura, mesmo que futura, para muitos profissionais, é determinada pela patologia. Por isso, cabe sempre a pergunta "quando é possível falar em cura?", pergunta que pode ser compreendida no sentido temporal (épossível falar em cura hoje?; devemos depositar nossas esperanças no futuro da psiquiatria como ciência?). E que pode ainda ser relançada com referência às expectativas que recaem sobre as várias patologias. De quais se pode esperar um prognóstico mais promissor? A historicidade da cura, presente nos dois sentidos da questão, é também levantada, em outros termos, por uma das psiquiatras entrevistadas (R2), numa interpretação que vem reforçar o enlace da cura com as concepções de normalidade e patologia sobre o qual temos insistido: Cura? É muito relativo isso. Esses dias eu assisti a uma jornada de neuropsiquiatria [...] Têm outras doenças que existiram naquela época e hoje são coisas tidas como normais, então cura 
em saúde mental é muito difícil e uma coisa que eu nunca vou ver como um fim, porque a saúde mental, o diagnóstico, em saúde mental, está muito ligado à perspectiva e à visão de sanidade.

Quando introduzi a questão da cura nas entrevistas com profissionais, com freqüência me deparei com respostas cuidadosas, cercadas de observações particulares acerca das várias patologias. No campo da multifatorialidade (teórica), as perspectivas de cura se delimitam entre a patologia e a compreensão etiológica que dela se tem, muitas vezes sendo a patologia o elemento determinante. A própria residente que há pouco enfatizava que a cura só pode ser historicamente situada, complementa seu pensamento dizendo que: Agora as psicoses não têm cura não, vai ter que tratar a vida inteira, cura, cura, cura, fechar, dizer está curado, não volta nunca mais, eu não vejo. Eu só fiz um ano deresidência, pela minha opinião, talvez daqui a um tempo eu mude de opinião, sabe, mas agora essa éa minha visão.

A enfermeira que nos disse ser perigoso falar em cura retrata também a impossibilidade de pensá-la se não especificamos claramente a que patologia nos referimos. Vejamos, com mais detalhe, o trecho do qual retiramos a frase que nos pareceu emblemática das sutilezas com as quais a cura se revela em psiquiatria.

O lha, é como eu estou falando para você, depende do caso. Depende do diagnóstico do paciente, que a gente sabe que uma esquizofrenia é difícil e você pensar numa cura, você pensa assim numa melhora prolongada. N uma compensação prolongada [...] Porque cura éuma coisa arriscada de você falar. Agora se você pensar assim num neurótico, Entendeu? Como nós todos somos neuróticos, mas tem aqueles neuróticos mais... deprimido, não é? Então você pode pensar, uma psicose puerperal, por exemplo, bom, é um paciente que pode ter uma psicose puerperal, uma mulher, só uma vez e nunca mais! Eu sei de um caso, que ela teve a psicose puerperal, compensou, passou um tempo usando a medicação hoje em dia está bem, trabalha, ativa, tem filho, foi depois desse filho. Também ela só teve esse filho. $Q$ ue às vezes a psicose puerperal se repete nas gestações. M as ela ficou em um. É uma pessoa equilibrada que trabalha, entendeu, sabe, resolveu as coisas dela, não usa mais medicação há anos e anos, o menino dela tem 11 anos.

A narrativa da enfermeira nos coloca questões de fundamental importância no campo psiquiátrico. Algumas que já discutimos, mas que valem novamente ser sublinhadas. (1) A perspectiva de cura se delineia a partir do diagnóstico e do prognóstico decorrente; (2) A cura poderia ser traduzida, no idioma psiquiátrico, como episódio único com remissão completa; (3) As perspectivas de cura (ou remissão completa) são muito raras nos casos de esquizofrenia; (4) A cura é freqü entemente substituída por um outro objetivo - a compensação.

Além da enfermeira, mais três psiquiatras se referem diretamente à incurabilidade da esquizofrenia e um quarto médico ressalta a incurabilidade das psicoses (nas quais se insere a esquizofrenia). Vejamos o que dizem dois psiquiatras e as comparações que traçam entre a esquizofrenia e outras patologias: [Você vê alguma perspectiva de cura em saúde mental?] $\mathrm{N}$ ão vejo. De cura não, a gente sabe que há alguns transtornos que você consegue uma remissão total, você pode falar, poderia falar em termos de cura, mas se vêcom o trabalho, que suspendendo a medicação, por exemplo, transtorno de humor, transtorno bipolar, de humor que a gente chama... É a psicose maníaco-depressiva, o paciente, [remite] totalmente, não tem mais nenhuma seqüela, como o esquizofrênico, que tem uma evolução processual. Ele apresenta um deterioramento progressivo. 0 paciente com transtorno de humor, ele remite totalmente, ele consegue exercer, tocar sua vida como eu, como você, como a maioria das pessoas, mas se vê, na maioria dos casos, quando interrompe o uso do tranqüilizante, do estabilizador do humor, alguns sintomas podem se manifestar (PSQ 4).

No caso do paciente psicótico não, eu não tenho [perspectiva de curar]. 0 paciente com síndrome do pânico, eu tenho. Eu determino quando ele chega. Aqui eu não tenho paciente com síndrome de pânico, mas quando ele chega no consultório, eu já digo para ele "ol he vamos nos tratar por um ano, éo tempo mínimo que eu tenho" [...] A gora, os pacientes psicóticos não, você tem esquizofrênico, paciente com transtorno afetivo, do humor, a antiga psicose maníaco-depressiva, são pacientes que vão ter um acompanhamento com prazo indefinido (PSQ6).

$\mathrm{Na}$ última narrativa, a esquizofrenia apare ce ao lado do transtorno do humor, pelo tempo indeterminado de tratamento, tomado como contraposto à síndrome de pânico. Contudo, no geral, o prognóstico para a esquizofrenia tende a ser pior do que no caso dos transtornos de humor (como apontava o PSQ 4) e outras patologias, por exemplo, a psicose póspuerperal citada pela enfermeira. 0 prognóstico desfavorável se deve, em parte, à categoriza- 
ção da esquizofrenia como uma doença crônica - o que não deixa de ser uma explicação tautológica: a esquizofrenia tem um prognóstico desfavorável porque é crônica e, por outro lado, é crônica porque tem um prognóstico desfavorável. Para melhor entender a cronicidade, vejamos a definição de doenças crônicas, segundo a Comissão de Doenças Crônicas, em 1957: [As doenças crônicas] Compreendem todas as deficiências [impairments] ou desvios do normal que têm uma ou mais das seguintes características: são permanentes; deixam uma incapacidade [disability] residual; são causados por alterações patológicas irreversíveis; requerem treino especial do paciente para sua reabilitação; requerem um longo período de supervisão, observação e cuidado (apud Dawson; Blum; Bartolucci, 1993).

Algumas idéias merecem destaque, pois nos auxiliam a entender por que a esquizofrenia é freqüentemente apontada como paradigma da incurabilidade. Estas seriam a permanência do impai rment, o caráter irreversível das alterações patológicas, o cuidado por tempo indeterminado e a idéia de treino no processo de reabilitação. A proposta de treinar doentes crônicos reforça o caráter imutável da doença, cuja inexorabilidade faz com que a terapêutica tenha, como principal função, a adaptação do sujeito ao ambiente do melhor modo possível.

Nos manuais, o curso (ou prognóstico) da esquizofrenia também não é favorável. Para o DSM - IV: A maioria dos estudos sobre curso e resultado da Esquizofrenia sugere que o curso pode ser variável, com alguns indivíduos exibindo exacerbações e remissões, enquanto outros permanecem cronicamente enfermos. A variabilidade na definição e na determinação impossibilita uma previsão acurada do resultado da Esquizofrenia a longo prazo. A remissão completa (i.e., um retorno ao pleno funcionamento pré-mórbido) provavel mente não é comum neste transtorno. Daqueles que parecem enfermos, alguns parecem ter um curso razoavelmente estável [ permanência de sintomas na ausência da fase aguda], enquanto outros apresentam uma piora progressiva associada com grave incapacitação. [Grifo nosso].

O prognóstico mais provável, portanto, varia entre a convivência com os sintomas até a cronificação com "grave incapacitação" que implica uma impossibilidade de cultivar laços sociais, sejam estes de trabalho ou afetivos. A perspectiva parece tão desfavorável que Kaplan $\&$ Sadock (1998) lembram, por exemplo, da teoria da decadência social, segundo a qual, independentemente da classe em que tenham nascido, os portadores de esquizofrenia tendem a piorar em termos de sua situação socioeconômica em decorrência da doença.

Caso acreditemos que a ciência se constrói por olhos ingênuos que coletam os fatos da realidade para posterior descrição, talvez 0 prognóstico desfavorável da esquizofrenia seja realmente um destino inexorável. N o entanto, desconfiando deste modo de conceber a construção do saber psiquiátrico, e concordando com a tese de que nossos ol hos são também guiados pelas teorias, cabe perguntar-nos se não seria útil colocar em suspensão a associação entre esquizofrenia e cronicidade, abrindo espaço para a construção de outros rumos. Quando o diagnóstico de esquizofrenia se torna uma condenação prévia à cronicidade, realmente só resta a "manutenção" e o "controle". $M$ as, se por outro lado, as expectativas sobre o curso do tratamento não estão completamente fechadas, talvez haja lugar para uma "salutar" contingência e o sujeito classificado como esquizofrênico surpreenda, rompendo com o lugar que culturalmente Ihe é reservado - 0 da solidão, ou seja, a ausência de laços sociais (fora do circuito médico).

Retornando aos psiquiatras entrevistados, a cura na esquizofrenia, quando surge como uma possibilidade futura, envolve geralmente a compreensão orgânica da doença. Por exemplo, a mesma psiquiatra (PSQ 6) que comparava a esquizofrenia com a síndrome do pânico afirma: Eu acho que a doença mental já teve um avanço muito grande e em algumas coisas a gente já consegue até fotografar. A gente sabe e eu sempre achei que a doença mental sempre tem um componente biológico. Não sei o que é, mas tem alguma coisa, porque se você pega dois indivíduos que passem pelas mesmas condições externas e pelo mesmo estresse, um vai desenvolver 0 processo patológico e outro não. Então tem alguma coisa, algum gene. [...] Porque são vários fatores, acho eu, há os fatores intrínsecos, acho que o indivíduo já vem com alguma coisa dizendo assim: vocêpode ser esquizofrênico, 0 outro aí fala que você tem uma tendência a ter um transtorno afetivo, vocêtem uma tendência depressiva. Em termos de depressão, o transtorno afetivo, já se vê vários, da serotonina, a gente já tem mais coisa. Em relação à esquizofrenia, não, então no dia em que a gente descobrir, para mim éuma coisa assim, está na cara, tão fácil, tão fácil que a gente não está percebendo, é como uma carta aberta. 
Enquanto 0 " $x$ " da questão não é descoberto, a psiquiatra evita falar com o paciente e sua família em termos absolutos: A gente não diz, eu mesmo não costumo dizer "não, ele não vai ficar bom". Q uem sou eu para tirar a esperança de alguém? Eu sempre digo "vamos continuar o tratamento, ele está tendo uma remissão social, ele pode ter outra crise como o indivíduo tem uma gripe, pode ter outra gripe".

A crença de que um dia a cura advirá é compartilhada com maior ou menor convicção por outros psiquiatras. Para al guns, a complexidade da etiologia é a causa mai or para a cautela quando se fala em cura: Acho que é muito complexa a esquizofrenia. Inclusive há duas teorias para explicar: uma é chamada organicista, que considera que é a psicose endógena, de causa somática, de causa desconhecida, etc. e tal; e tem a teoria psicodinâmica, que é a de conflitos adquiridos no desenvolvimento de vida e tal... M as ninguém nunca conseguiu provar (PSQ 2).

$O$ interessante, no caso do psiquiatra citado é que, não obstante ele reconheça a dificuldade de pensar na cura, num campo em que a etiologia é uma areia movediça, depois de 28 anos de profissão, altera sua fala mansa e jeito reservado, para afirmar com convicção que acha que a cura advirá com o avanço dos conhecimentos científicos. Aliás, afirmativa que ele mesmo trata de destacar: "acho não, tenho certeza".

A etiologia é também retomada pela PSQ1 que, pensando no futuro da psiquiatria, consegue vislumbrar melhores perspectivas para os transtornos de humor, talvez seja mais no nível de engenharia genética, não sei se através de me dicação, dos remédios. No entanto, permanece em dúvida com relação ao futuro das patologias que considera serem essencialmente de ordem dinâmica. Neste ponto, introduz a questão dos limites da psiquiatria no tratamento de todas as patologias: Têm algumas patologias que são muito de ordem dinâmica. Eu não sei, assim, como é que seria, dependeria de muita coisa. Porque quando a pessoa chega, ela vem com aquela queixa. Eu estou com insônia. Eu não durmo há um mês. Assim começa. Aí você vai abrindo assim uma coisa. Ela começa do núcleo familiar dela e das pessoas, depois vai ficando mais amplo. Vai le vando. Então eu teria que pressupor uma situação ideal de vida para todos. Eu não sei como équeno caso das neuroses, por exemplo, neurose como patologia psiquiátrica. Eu não sou psicanalista. Então eu não sei é se seria possível isso, se você considera a medicina só. A medicina dá conta disso? A psiquiatria dá conta disso? Eu não sei...
No campo onde florescem as esperanças, a aposta do PSQ 3 é mais específica e se refere ao desenvolvimento do projeto genoma e das neurociências, apesar de o psiquiatra reconhecer que, com relação ao estudo das imagens, "ainda é uma teoria fraca". 0 desenvolvimento de novas drogas seria uma conquista já al cançada no sentido da cura, especial mente nos casos de depressão e transtornos obsessivo-compulsivos, em que as novas medicações estariam produzindo resultados importantes.

Com relação ao mapeamento do cérebro através das neurociências, o psiquiatra residente, identificado como R1, mostrou-se também entusiasmado e nos trouxe uma metáfora que vale ser retomada. Quando Ihe perguntei acerca das possibilidades de cura, ele me respondeu, inicialmente, que algumas patologias já são curáveis como, por exemplo, neuroses (posição diferente da PSQ 1), transtornos de ansiedade, síndrome do pânico, agorafobia e fobia social. Com relação às perspectivas de cura para as doenças que hoje são tidas como incuráveis, como é o caso da esquizofrenia, ele me respondeu: U ma perspectiva sempre existe. Porque se está encaminhando, a cada dia se descobre alguma coisa. Agora eu sempre digo que a psiquiatria ainda está na Idade M édia, na época da sangria. Eu sempre costumo falar isso.

Fiquei intrigada com a localização da psiquiatria na I dade M édia e imaginei que o motivo da comparação estava nas práticas empregadas pela psiquiatria, como a internação, ou mesmo, a contenção e o el etrochoque. $M$ as não se tratava disso. Para o psiquiatra recém-formado, a psiquiatria está na I dade M édia pelo nível de conhecimento atingido: Talvez seja exagero. Já se tem noção de algumas áreas do cérebro relacionadas, algumas áreas de atrofia ou de hiperatividade no cérebro, relacionadas com alguns tipos de patologias diferentes, mas não se sabe exatamente... São evidências [...] H oje a psiquiatria biológica está se desenvolvendo muito. N os últimos 20, 10 anos. Ela vem se desenvolvendo muito e um de seus novos [ progressos] foi o avanço da neuro-imagem... A cho isso uma grande perspectiva para se localizar exatamente..

Enquanto 0 avanço da psiquiatria para alguns é um fato, com todas as polêmicas que possa envolver, para outro psiquiatra (PSQ 5), o entusiasmo deve ser analisado com cautela. Indagado sobre perspectivas de cura, ele nos responde: Não, visualizar cura não, no momento não, pelo menos, o que eu leio, até em função dos residentes, essa parte da psiquiatria mais 
biológica, eu procuro me manter um pouquinho atualizado, apesar de não gostar dessa coisa só de neurotransmissor subindo e descendo, entrando e saindo do neurônio, isso para mim éo fim da picada. Mas até onde eu sei, não tem nenhum grande avanço, ainda não. 0 que se tem falado, nos últimos dois, três anos, é da terapia cognitiva, mas agora as publicações que fizeram a maior festa no início, já estão começando, alguns artigos bastante desacreditados com relação às terapias comportamentais de modo geral. Então, quer dizer, do ponto de vista farmacológico, biológico mesmo, orgânico, não tem nada de novo.

\section{Considerações finais}

Como é visível, a multivocalidade é a regra quando a cura é o tema na psiquiatria, especialmente quando se trata de projeções para o futu- ro. Algumas similaridades podem ser traçadas: a cura como episódio único com remissão total dos sintomas; a primazia do biológico, nos modos de interpretar e agir; e a adoção da esquizofrenia como a encarnação da incurabilidade e da cronicidade. No entanto, as diferenças com relação à avaliação dos poderes de cura, atuais e futuras, na psiquiatria são significativas. Diferenças que se devem, em grande parte, às outras afinidades teóricas dos psiquiatras entrevistados, haja vista que nem só do orgânico vive a psiquiatria. A presença de correntes teóricas como a psicanálise e as terapias comportamentais têm uma influência direta na conduta clínica e nos processos de significação da cura dos nossos entrevistados. Em linhas gerais, a multivocalidade se sustenta na compreensão etiológica do transtorno mental, nas expectativas acerca do curso de cada patologia em particular, bem como do futuro da psiquiatria.

\section{Referências bibliográficas}

Bezerra JR B 1992. Considerações sobre terapêuticas ambulatoriais em saúde mental no Brasil, pp. 133-169. In NR Costa \& SA Tundis (org.). Cidadania eloucura: políticas de saúde mental no Brasil. Ed. Vozes, Petrópolis.

Dawson D, Blum H \& Bartolucci G 1993. Schizophrenia in focus: guidelines for treatment and rehabilitation. Human Sciences Press, N ova York.

GoldbergJ 2001. Reabilitação como processo - o Centro de Atenção Psicossocial (CAPS), pp. 33-47. In A Pitta. Reabilitação psicossocial no Brasil. Hucitec, São Paulo.

Hydén L-C 1995. The rethoric of recovery and change. Culture, M edicine and Psychiatry 19:15-21.

Kaplan H \& Sadock B 1998. M anual de Psiquiatria Clínica. Ed. Artmed, Porto Alegre.

Kleinman A 1978. Concepts and a model for the comparison of medical systems as cultural systems. Social Science and M edicine 12:85-93.
Kleinman A \& Sung L 1979. Why do Indigenous Practioners Successfully $\mathrm{H}$ eal? Social Science and M edicine 13B:07-26.

Laplantine F 1991. As formas elementares da cura: os modelos terapêuticos, pp. 161-209. In F Laplantine. Antropologia da doença. Ed. Martins Fontes, São Paulo.

Lévi-Strauss C 1975. A eficácia simbólica, pp. 215-236. In C Lévi-Strauss. Antropologia estrutural. Ed. Tempo Brasileiro, Rio de Janeiro.

$M$ anual Diagnóstico e Estatístico de Transtornos $M$ entais (DSM - IV -TR) 2002. Ed. Artmed, Porto Alegre.

Sinding C 1995. Un modele en M orceaux, pp. 4-7. La Recherche (Supplement): La Santé et ses M etamorphoses, nov.

Teixeira M, 1999. Algumas reflexões sobre o conceito de cura em psiquiatria. Cadernos IPU B: por uma Assistência Psiquiátrica em Transformação 3:85-94.

Artigo apresentado em 20/07/2004

A provado em 25/08/2004

Versão final apresentada em 25/08/2004 